\title{
TRUST ISSUES: EVIDENCE FROM SECOND GENERATION IMMIGRANTS
}

\author{
Martin Ljunge ${ }^{1}$ \\ University of Copenhagen and SITE
}

April 21, 2012

\begin{abstract}
This paper estimates the intergenerational transmission of trust by studying second generation immigrants in 29 European countries with ancestry in 87 nations. There is significant transmission of trust on the mother's side. The transmission is stronger in Northern Europe. Ancestry from more developed countries suggests a stronger transmission of trust, but the heterogeneity in ancestry dissipates for individuals who reside in Northern Europe. The results suggest an interaction between cultural background and current institutions, where building trust in Northern Europe is a long process but the adjustment to the trust levels in Southern and Eastern Europe is fast.

JEL codes: D13, D83, J62, Z13

Keywords: intergenerational transmission, trust, immigrants, cultural transmission, integration of immigrants
\end{abstract}

\section{Introduction}

Trust has been shown to correlate with favourable economic outcomes (Knack and Keefer 1997) and with indicators of good government (La Porta et al. 1997 and 1999) in cross country data. Recent papers examine the causality of trust on outcomes by instrumental variables within countries. The focus has been on historical political institutions that transmit trust, which in turn affect income (Tabellini 2008 and 2010) and social capital (Guiso et al 2008). Algan and Cahuc (2010) use the trust measures of different waves of immigrants to the U.S. to obtain a measure of how trust has changed over time, which they regress on growth to estimate a causal effect of trust on growth across countries. The evidence points to an important role for trust in economic and social development, but the knowledge of how trust is formed at the micro level is limited.

\footnotetext{
${ }^{1}$ Contact: University of Copenhagen, Department of Economics, $\varnothing$ ster Farimagsgade 5, building 26, 1353 København K, Denmark, martinljunge@gmail.com. I acknowledge financial support from the Riksbanken Tercentenary Foundation.
} 
Intergenerational transmission of trust in the family is examined by Dohmen, Falk, Huffman, and Sunde (2011) using a survey in Germany that samples both parents and their adult children. They find strong positive correlations between the parents' and their children's trust attitudes, which is consistent with a causal effect of parental trust on children's trust. To address potential concerns about reverse causality they apply an instrumental variables approach. However, as pointed out by the authors, the results should only be seen as suggestive of a causal effect due to a lack of good instruments.

The objective is to build on this work and provide an estimate of the intergenerational transmission of trust using a different method; a method with a stronger claim to estimating a causal effect. I study how second generation immigrants' trust are affected by the average level of trust in the parent's birth country. This approach avoids the reverse causality issue. The average level of trust in the parent's birth country is not influenced by the trust of the child, who is born in and resides in a different country.

Some evidence of intergenerational transmission of trust among immigrants is given by Guiso, Sapienza, and Zingales (2006). They regress trust on ancestry country or region fixed effects for immigrants in the US. The fixed effects would not only directly capture the cultural influence of trust from the country of ancestry but also other aspects of cultural transmission. They find that the average level of trust in 14 immigrant groups is correlated with average trust in the corresponding countries. In a regression analysis of immigrants in the U.S. Algan and Cahuc (2010) find that trust is significantly related to trust in their ancestral country. They consider immigrants from 24, primarily European, countries. ${ }^{2}$

The current literature has not considered the intergenerational transmission of trust in a broad range of countries, nor has it considered individuals from a wide set of backgrounds. I add to the literature on intergenerational transmission of trust in several ways. First, I study individuals who reside in 29 European countries, which display a rich variation in the institutional and cultural environment individuals' face. Such variation increases the validity of the results as immigrants to the U.S. could be particular and the results in that environment may not generalize. Second, I consider immigrants from 87 countries of ancestry which include not only Europe but also a wide range of countries in Africa, the Americas, and Asia. By decreasing the reliance on immigrants from one region, Europe, which could be different from individuals in other regions, my results can address if Algan and Cahuc's (2010) are general or specific to European immigrants in the U.S.

\footnotetext{
${ }^{2}$ Tabelllini (2008) presents similar evidence on immigrants in the U.S. from 21, primarily European, countries. Also see Uslaner (2008) on immigrants in the U.S. from 9 regions.
} 
Third, I examine the heterogeneity of the intergenerational transmission of trust. I study if the transmission is stronger for individuals residing in certain countries or with certain ancestral roots. I also examine if certain individual characteristics, such as being more integrated or having a highly educated mother, are associated with different influences of ancestral trust. The current literature has not addressed the heterogeneity of the intergenerational transmission. The heterogeneity estimates provide evidence on which channels are stronger and what the complementary influences are.

Fourth, I study a determinant of trust in the ancestral country. The factor I examine is language structure, in particular if pronoun drop is allowed and if there is second person pronoun differentiation (such as Tu-Vous in French). These linguistic features may indicate different levels of respect for the individual, which in turn may affect trust. ${ }^{3}$ While the regressions of second generation immigrants provide a natural experiment in itself, they take the trust level of the ancestral country as given. The objective of using language structure is to understand what drives trust in the ancestral country. ${ }^{4}$ The second step is to use the part of the ancestral country trust that is shifted by the language structure and relate it to the individual trust of the second generation immigrants. This approach combines two distinct methods in the literature in a novel way.

I find evidence of significant cultural transmission of trust, which is strongest on the mother's side. There is also evidence of intriguing heterogeneity. The transmission seems much sturdier in certain contexts. The transmission is strong for individuals born and residing in Northern Europe and weaker elsewhere. There is also heterogeneity in the transmission based on ancestry. The evidence points to a stronger transmission channel for individuals with ancestry from western nations, in the full sample. However, when the analysis is restricted to individuals residing in Northern Europe the estimates indicate no difference in the transmission based on ancestry. The results point to an interaction between cultural background and current context. The results are consistent with individuals who adjust quickly to the trust levels in Southern and Eastern Europe, no matter their ancestry. Adapting to the higher trust in Northern Europe is a long process as captured by the intergenerational transmission estimates. ${ }^{5}$ The evidence fits with previous findings that social capital can depreciate quickly, but it takes a long time to build. ${ }^{6}$

\footnotetext{
${ }^{3}$ These features have been used in the literature to address different questions in cross-country analysis, see Licht et al (2007) and Tabellini (2008).

${ }^{4}$ Similar in spirit is Durante (2010) who uses weather patterns as shifters of risk sharing institutions.

${ }^{5}$ As an example, the share of the population in Sweden who say that most people can be trusted is twice that of Italy.

${ }^{6}$ See for example Nunn \& Watchekon (2011).
} 
The approach of regressing individual outcomes on ancestral country values, labelled the epidemiological approach in Fernandez (2010), has been used to examine a range of questions. ${ }^{7}$ Studies using variants of this strategy have found strong effects of cultural traits in explaining aspects of women's labour supply and fertility (see e.g., Guinnane et al 2006; Alesina and Giuliano 2010; Fernandez 2007; Fernandez and Fogli 2006 and 2009), and youth employment and mobility (Alesina and Giuliano 2010). Most evidence has been based on immigrants to the U.S. A few recent papers use data from a broad range of European countries to study motivation behind political participation (Alesina and Giuliano, 2011) and preferences for redistribution (Luttmer and Singhal, 2011). The same data, the European Social Survey, is at the core of the analysis in this paper. Trust among first generation immigrants in Europe is examined by Dinesen (2011). He takes a different approach by using cross country variation to estimate effects of residence country institutions. I follow the approach in the economics literature and use within country variation. ${ }^{8}$

Trust is not only determined by the cultural environment but also by institutions, as discussed by Guiso et al (2006). My approach singles out the cultural component of trust and its transmission in the family. The second generation immigrant is influenced by the cultural and institutional environment where they are born and reside. In addition, he may be influenced by the socialization by the immigrant parents. The influence is restricted to the cultural part since the child is separated from the institutions of the parent's birth country. The parents influence the child through direct vertical socialization as modelled by Bisin and Verdier (2001). Since the second generation immigrant is not subjected to the institutional environment of the ancestral country he is not subject to the same horizontal cultural transmission as his parents. If there is a complementarity between direct and vertical transmission, the study of second generation immigrants may fail to detect the cultural transmission although it is there. In this sense the estimate of the direct cultural transmission is biased towards zero, and hence conservative.

The remainder of the paper proceeds as follows. Section 2 discusses the empirical specification, followed by the description of the data in section 3. The results are presented in section 4, and section 5 concludes.

\section{Empirical Specification}

I run a number of ordinary least squares (OLS) regressions of the following form: ${ }^{9}$

\footnotetext{
${ }^{7}$ Fernandez (2010) presents a detailed discussion of the approach as well as an extensive survey of papers applying the approach.

${ }^{8}$ Dinesen (2011) uses a random effects model with very different interpretation from the fixed effect model used in this paper. Furthermore, I make weaker assumptions on the error terms. I allow for arbitrary correlations among individuals with the same ancestry where the random effects model assumes independence.

${ }^{9}$ The results are robust to using the ordered logit or the ordered probit estimator.
} 


$$
\text { Trust }_{\text {icat }}=\beta_{0}+\beta_{1} \text { Mean_Trust }{ }_{a}+\beta_{2} X_{i}+\gamma_{c t}+\varepsilon_{\text {icat }}
$$

Trust $_{\text {icat }}$ captures the trust of individual $\mathrm{i}$, born and residing in country $\mathrm{c}$ with a parent born in country $\mathrm{a}$, and $a \neq c$, in period $t$. The average level of trust is common to all individuals with a parent born in country $a . X_{i}$ captures individual demographic and economic controls that may affect trust. The country of residence-byyear fixed effect $\gamma_{\mathrm{ct}}$ captures all the unobserved factors that may affect trust differentially across countries and time, and $\varepsilon_{\text {icat }}$ is the error term. All standard errors allow for clustering by the parent's birth country.

The advantage of this empirical model, over the analysis in for example Dohmen et al (2011), is that the parental trust measure is not endogenous to individual i's trust. A significant estimate of $\beta_{1}$ would hence indicate an impact of the trait in the country of ancestry on the individual outcome and not the other way around. Reverse causality is not a concern since the trust of a child born and residing in country c can't affect the average value of trust in the parent's birth country a. Confounding factors are of course a concern so it is important to include an extensive list of individual controls in $X_{i}$, which is done. The inclusion of the country fixed effect $\gamma_{\mathrm{ct}}$ means that I account for the institutional structure and all other unobserved differences which apply to all residents in country $\mathrm{c}$ in period $\mathrm{t}$. It also means that the variation used is to compare the outcomes of second generation immigrants within each country of residence relative to the traits in their countries of ancestry. ${ }^{10}$ The country fixed effect is included for each year, which controls for non-linear trends that may differ across countries.

Moreover, the empirical approach produces a conservative estimate of $\beta_{1}$. The underlying model would be that the parent's individual trust would affect the child's trust, but I use the average of the trust in the parent's birth country as a shifter that is not influenced by the child's trust. Since there is substantial variation of parents' individual trust levels in a population the average level of the trust in the parent's birth country, the variable Mean_Trust ${ }_{a}$ in the analysis, is not perfectly related to the parent's individual trust. This produces an attenuation bias in the method, biasing the estimate of $\beta_{1}$ toward zero. The estimate of $\beta_{1}$ is hence conservative, and finding a significant effect in spite of this bias would be strong evidence that the effect is present.

\section{Data}

The European Social Survey (ESS) is the main data set. The survey is administered biannually, starting in year 2002, in a wide range of European countries. The survey covers a broad range of questions on social,

\footnotetext{
${ }^{10}$ For example, I am comparing if individuals with high trusting Swedish ancestry born in Germany have higher trust than those born in Germany with lower trusting Italian ancestry.
} 
political, and economic conditions, as well as demographic variables. Data from the first five rounds of the ESS are used.

One essential feature of the data is that the survey asks about the country of birth of the respondent as well as the country of birth of both parents. ${ }^{11}$ This information allows me to identify second generation immigrants and which countries their parents originate from. Looking at many countries of residence for second generation immigrants, 29 countries are studied, reduces the concern that the results are driven by conditions of one particular country. Individuals with ancestry from a wide range of countries are observed, up to 87 countries across the world, that reduce the concern that the results are particular to a small number of ancestral backgrounds.

The summary statistics are presented in Table A1. The countries participating in the ESS in each round are presented in Table A2. The table also shows the regional classifications.

\subsection{Individual Trust}

Individual trust is measured with the following question in the ESS: "Using this card, generally speaking, would you say that most people can be trusted, or that you can't be too careful in dealing with people? Please tell me on a score of 0 to 10, where 0 means you can't be too careful and 10 means that most people can be trusted." I use the same coding of the answers as presented in the question. A higher value measures higher trust as it signals a stronger agreement with the statement that most people can be trusted.

\subsection{Control Variables}

The ESS includes a rich set of individual controls. Age, gender, marital status, education, employment status, income, and religious affiliation are observed. Marital status is captured by two dummies for married and never married, with widowed and divorced being the excluded category. Education is captured by one dummy for tertiary (university) degree and above, and one dummy for upper secondary as the highest attained degree. Lower education is the excluded category. One dummy captures individuals who are out of the labour force (students, not employed and not looking for work, and retired), and another dummy for unemployed who look for work. The employed is the omitted category. Income is measured by income decile, based on the country specific income distribution. I create one dummy for the bottom three deciles, Low Income, and one dummy for the middle four deciles, Middle Income. There are three dummies for the following religious denominations: Catholic, Protestant, and Orthodox. All other denominations are in the excluded category.

\footnotetext{
${ }^{11}$ This information is available from the second wave of the ESS, the first wave is hence not used in the analysis. Extensive documentation of the data is found at http://ess.nsd.uib.no/.
} 
In addition to the mother's and father's country of birth there are a few parental characteristics I use. There is information on the parent's highest level of education, which are captured by dummies for tertiary and upper secondary degrees as for the individual himself. There is also information on the mother's and father's employment status when the respondent was 14 years old, and a dummy captures if the mother and father was employed.

\subsection{Trust in the Parent's Country of Birth}

Average trust in the parent's country of birth is computed in the integrated European Values Survey and the World Values Survey (EVS/WVS). This allows me to expand the analysis of second generation immigrants beyond those with ancestry in the countries covered by the ESS. In the EVS/WVS trust is observed for 87 nations, which is three times the number of countries in the ESS. Moreover, the countries in the EVS/WVS are much more diverse and include countries from Africa, the Americas, and Asia. ${ }^{12}$ The trust questions are worded similarly in the ESS and the EVS/WVS.

The question regarding trust in the EVS/WVS is "Generally speaking, would you say that most people can be trusted or that you need to be very careful in dealing with people?" The possible answers are "Most people can be trusted," which is coded as 1 , and "Can't be too careful," which is coded as 0 . The average of this variable is computed for each country across the waves in which the question is asked. The average is increasing in trust, that is, the higher the fraction who answers that most people can be trusted.

\section{Results}

I find strong evidence of cultural transmission of trust. The individual trust of second generation immigrants is influenced by the level of trust in the parent's country of birth. The effect is particularly pronounced for individuals with an immigrant mother. The transmission is stronger for individuals who are born and reside in Northern Europe.

\subsection{Ancestral Country Trust and Its Influence on Second Generation Immigrants}

I begin by analysing the sample with an immigrant mother. Apart from including the mean trust in the mother's country of birth I only include the most exogenous individual characteristics age and its square, and gender as controls in the first specification in Table 1. All regressions also include a full set of country of residence-by-year fixed effects. The point estimate on trust in the mother's country of birth is positive and strongly significant. It means that second generation immigrants with a mother from high trusting countries tend to have higher trust levels than other individuals who live in the same country. All the second

\footnotetext{
${ }^{12}$ Extensive documentation of the data is available at www.worldvaluessurvey.org.
} 
generation immigrants are born and reside in the same country but those with mother's from higher trusting countries systematically express higher trust. It is possible that the individuals with different ancestry differ in other characteristics, which in turn affect trust. This is taken into account by including controls for a range of individual characteristics that the literature has shown to be important. ${ }^{13}$ I control for marital status, education, employment status, income, and religion. The point estimate on trust in the mother's birth country remains strongly significant. Of the individual controls education is strongly related to higher trust as are Protestants. The influence of trust in the mother's country of birth is quantitatively significant. A one standard deviation increase in the trust of the mother's country corresponds to the individual reporting higher trust by 0.2 points, which correspond to .08 of a standard deviation of individual trust. ${ }^{14}$ The magnitude corresponds to the difference in trust among those in the bottom three deciles of the income distribution compared to the top three deciles. The effect also corresponds to half the effect of having an upper secondary degree (compared to less education). The magnitudes are comparable to those for the transmission of redistributive preferences among first generation immigrants in Luttmer and Singhal (2011).

The literature has considered some additional individual controls for explaining trust. Religiosity has been examined by Berggren and Bjørnskov (2011) in a cross country analysis. Uslaner (2002) argues that optimism is an important determinant of trust, as well as attitudes towards inequality. My results are robust to including these controls but I don't report them in the baseline specification since their exogeneity is not clear. ${ }^{15}$ Furthermore, some of the intergenerational transmission of trust could operate through these channels. Hence, including them as controls would shut down potentially important ways in which trust is transmitted across generations.

The analysis is repeated for the sample with an immigrant father in specifications 3 and 4 of Table $1 .{ }^{16}$ The point estimate on trust in the father's birth country is positive as in the immigrant mother sample, but the estimate is not significant. This does not mean that fathers have no influence on the child's trust, in particular since the method has a built in attenuation bias, but that the transmission isn't strong enough.

All the available data is used in the results presented. There may be a concern that including ancestral countries with few second generation immigrants introduce noise into the estimation. I don't find this to be

\footnotetext{
${ }^{13}$ See for example Alesina and La Ferrara (2002).

${ }^{14}$ Individual trust is measured on a 10 point scale, while the trust in the parent's country of birth is measured on the unit interval.

${ }^{15}$ I use the degree of religiosity, happiness to capture optimism, and preferences toward redistribution to capture attitudes towards inequality.

${ }^{16}$ There is some overlap in the sample since some individuals have parents who both are immigrants.
} 
the case as results are similar if I require there to be at least 15 immigrants from an ancestral country, as practiced by Algan and Cahuc (2010). ${ }^{17}$

It is possible that immigrants are overcompensating their attitudes to counteract stereotypes of the ancestral country. For example, individuals with ancestry from low trust countries could be very trusting as a response to the expectation that people with that ancestry have low trust. Such behaviour would however attenuate the estimated coefficient on trust in the ancestral country, and it could not explain the significant relationships estimated.

Selection of immigrants is not necessarily a problem for the analysis. First, the second generation immigrants have not chosen to emigrate, and being born and raised in the country of residence they are integrated in society, which attenuates such concerns. The second generation immigrants also look similar to the general population on observables and the estimates on the demographic variables are similar. ${ }^{18}$ Even so, the estimates would not be affected by selection if it is uniform. For example, if only high trust individuals choose to emigrate it would not necessarily affect the estimate since only variation in differences, not levels, across ancestries is used to identify the estimates. Furthermore, if there is positive sorting so that high trust individuals move to high trust countries, and that the hypothesis of cultural transmission of trust is true, this would compress the variation in the left hand side variable and bias the estimate toward zero.

\subsubsection{Ancestral Country Characteristics}

Table 1 addressed the concern that individual characteristics are correlated with trust in the parental birth country. Another concern may be that other characteristics of the parent's birth country are correlated with trust, which could confound the estimate. As countries with higher income tend to be more trusting I want to separate these effects. Table 2 includes the natural logarithm of the gross domestic product (gdp) per capita in the parent's birth country. The following regressions also include the extensive set of individual controls included in Table 1 (columns 2 and 4 ) as well as country-by-year fixed effects. The results for the sample with an immigrant mother are in specification 1 in Table 2. The estimate on trust in the mother's birth country remains strongly significant and similar in magnitude. The results can't be explained by the level of income in the country of ancestry. Another concern may be that political institutions correlate with trust, as more democratic countries tend to display higher trust. Specification 2 adds the polity2 variable from the Polity IV project in the mother's birth country. ${ }^{19}$ The influence of trust remains,

\footnotetext{
${ }^{17}$ The results are also robust to cut-offs at 5, 10, or 25 observations per ancestral country.

${ }^{18}$ For a comparison on estimates on the demographic variables see Table A4.

${ }^{19} \mathrm{~A}$ higher value of the variable captures more democratic institutions.
} 
and neither income nor political institutions are significant. Another measure of institutional quality is the Rule of Law index from the World Bank Development indicators. ${ }^{20}$ The measure includes perceptions of the incidence of crime, the effectiveness and predictability of the judiciary, and the enforceability of contracts. ${ }^{21}$ The Rule of Law in the mother's birth country is added to the specification in column (3) of Table 2 . The estimate on ancestral trust remains strongly significant, while the other ancestral variables are insignificant.

Income, political institutions, and the rule of law are added to the model estimated on the sample with an immigrant father. The point estimates on mean trust are slightly larger than in the baseline but remain insignificant. The estimate on ancestral trust is the most precise in column (6) with a p-value of 0.116 . Notable is the strongly significant effect of the Polity2 variable in the father's birth country. It indicates that democratic institutions help to foster trust among individuals in the second generation, who themselves are removed from those institutions. ${ }^{22}$ The results indicate an interesting heterogeneity in the transmission of trust between mothers and fathers. The transmission on the mother's side is driven by the trust beliefs but on the father's side the trust transmission is driven by more democratic political institutions. This heterogeneity finding is a novel contribution to the literature.

\subsubsection{Parental Characteristics}

There may be concerns that the parents who emigrate from high trusting countries are particular compared to others. In particular, these parents may have higher education levels, which may translate into higher trust of the child. ${ }^{23}$ I control for the parent's level of education (highest attained), as well as their employment when the individual was 14 years of age. The results are robust to adding these controls as seen in Table 3. The estimates of trust in the mother's birth country, although slightly smaller in magnitude, remain strongly significant. Trust in the father's country of birth remains positive but insignificant. Another result from Table 3 is that parental education has a positive impact on the child's trust conditional on all the other covariates. The result is the strongest and most robust with respect to tertiary education. The estimates are quite similar for mother's and father's education. Several specifications also indicate a positive effect of upper secondary education. Having a working father, at age 14, has a strong positive effect on the child's trust, while no such effect is estimated for mothers.

\footnotetext{
${ }^{20}$ Data and documentation are available at http://www.govindicators.org.

${ }^{21}$ For example Berggren and Jordahl (2006) find that institutional quality and property rights are associated with trust across countries.

${ }^{22}$ The current political institutions are captured by the country of residence fixed effect.

${ }^{23}$ However, I control for the individual's education level, which may capture the main effect of transmission of trust through education. Moreover, parental selection would not be a concern as long as it's common across ancestral backgrounds since only within country of residence variation is used.
} 


\subsection{Heterogeneity}

I consider heterogeneity in several dimensions. First is the issue if the current context matters for the cultural transmission, where I examine the influence of country of birth and residence for the second generation immigrants. Second, I examine if the transmission is influenced by the ancestral country. Third, I examine if individual factors, like being more integrated or having a highly educated mother, affect the transmission of trust. I only present estimates for individuals with an immigrant mother in order to conserve space. Estimates with the immigrant father sample show the same pattern as for mothers but estimates are less precise.

\subsubsection{Current Context}

Previous studies of the intergenerational transmission of trust, such as Algan and Cahuc (2010) and Dohmen et al (2010), have only studied one country (the U.S. or Germany). Luttmer and Singhal (2011) study the transmission of redistributive preferences in a range of countries but they do not examine if there is a differential effect across countries of residence.

I estimate if the cultural transmission of trust differs across environments. Does the cultural transmission for second generation immigrants with the same ancestry depend on where the child is born and reside? I find that it does. First, I distinguish between second generation immigrants in Western and Eastern Europe. ${ }^{24}$ I interact the trust in the mother's country of birth with an indicator of the area of residence. The result is presented in model $\mathrm{A}$ in Table $4 .{ }^{25}$ The point estimate is higher for those second generation immigrants born in Western Europe compared to the East, although the difference is not significant at conventional levels. ${ }^{26}$ In model B in Table 4 I separate Western Europe into Northern and Southern Europe. ${ }^{27}$ It reveals a significant difference between immigrants in Northern and Southern Europe, where the estimate for individuals in Northern Europe is positive and significant. The differences across groups are now statistically significant at conventional levels. In model C I restrict the sample to residents in Western Europe to avoid an influence from the relatively noisy Eastern Europe. The estimates in model $\mathrm{C}$ are very similar to model B as seen in Table 4. The difference between the North and the South remains statistically significant.

The evidence points to significant differences in the intergenerational transmission of trust. The transmission is stronger in Northern European countries, which exhibit higher trust than Southern

\footnotetext{
${ }^{24}$ The divide between Western and Eastern Europe follow the cold war division. See Table A2 for details.

${ }^{25}$ The regressions include the individual controls and country-by-year fixed effects as in Table 1.

${ }^{26}$ The very large standard error for the Eastern Europe estimate reveals a lot of heterogeneity in this group.

27 Northern Europe includes Austria, Belgium, Denmark, Finland, Germany, Holland, Ireland, Lichtenstein, Norway, Sweden, Switzerland, and United Kingdom. See Table A2 for further details on country classifications.
} 
European nations. The second generation immigrants in the north have not converged to the trust levels in those countries. In Southern Europe there is no significant relationship between individual and ancestral trust, consistent with an adaptation to the local equilibrium by the second generation immigrants born in this environment.

The differences in the strength of the transmission of trust across Northern and Southern Europe can be understood through a model like Butler, Giuliano, and Guiso (2011). In the model high trusting individuals choose to interact with others in society more than low trusting individuals, since high trusting individuals have a higher expected payoff given his subjective probabilities on the other party being trustworthy. When a high trusting individual interacts in a low trusting context he will soon be cheated and update his trust. Before long his trust will have dropped to a level appropriate for the low trust context he is in. Low trusting individuals rarely interact even in a high trust context. He hence has few opportunities to update his trust to the higher level that would be beneficial in the high trust environment. The increase in trust is hence slow. My evidence suggests that this process has yet to converge by the second generation.

The estimates will not necessarily be influenced by selective migration if selection is uniform across ancestral countries, as discussed earlier. If selection is positive so that relatively high trust parents migrate to high trust countries the estimate could be affected but the bias would be toward zero. The reason is that positive selection, if the hypothesis of cultural transmission is true, would tend to suppress variation in the dependent variable trust among second generation immigrants.

Note that the result should not be interpreted as a positive effect from welfare state institutions on trust for all immigrants. ${ }^{28}$ The effects of such institutions are captured by the country fixed effect. Since within country variation is used the estimate tells us that immigrants from low trust countries remain systematically below the average trust level, and the distance is proportional to the trust in the ancestral country.

\subsubsection{Ancestry}

I examine if the intergenerational transmission of trust differs by ancestry. The previous literature has assumed that the transmission mechanism is the same no matter the ancestry. I find that there are significant differences across ancestry. However, these differences seem to depend on where the immigrants are residing, indicating an interaction between heterogeneity in ancestry and current context.

\footnotetext{
${ }^{28}$ The relationship between welfare state institutions have been analyzed by Bergh and Bjørnskov (2010) and Kumlin and Rothstein (2005), among others.
} 
First I distinguish immigrants with ancestry in richer and more developed countries from others. I separate people based on ancestry in Western Europe and compare them to those with ancestry elsewhere. I interact this dummy with the trust in the mother's country of birth. The results for the full sample are presented in model A in Table 5. The point estimate for those with Western European ancestry is larger than the estimate on those with other ancestry. The estimates are, however, not significantly different. The point estimates present suggestive evidence of a difference. In model B the sample is restricted to second generation immigrants residing in Western Europe. Both estimates are now larger in magnitude and significantly different from zero. The difference between the point estimates is smaller both in absolute and relative terms. The convergence is also reflected in the $p$-value for the test of equality, which is now larger. The increasing magnitude and convergence of the two estimates is further accentuated in model $\mathrm{C}$ where the sample is restricted to residents in Northern Europe. Table 5 suggests that there is heterogeneity in ancestry when studying a broad set of countries, but that this difference dissipates as residents in richer and more trusting societies are studied. The results are robust to cutting the interaction term by the mother being born in Europe or in the OECD.

Next I study ancestry across five continents: Europe, North America, Latin America, Africa, and Asia. ${ }^{29}$ An indicator for ancestry from the continents is interacted with the trust in the mother's birth country. The estimates for the full sample are presented in model A in Table 6. The coefficients on the interaction terms with Europe and North America are positive and significant. The point estimate for Latin America is large but dwarfed by the standard error. The F-test of equality across ancestral continents is rejected with a pvalue of $3.6 \%$. There is hence evidence that the intergenerational transmission differs across ancestry. In model B I restrict the sample to residents in Western Europe. All point estimates increase in magnitude, but only those from Europe and North America are significant. The F-test does no longer reject equality of the estimated coefficients with a p-value of $20 \%$. In model C in Table 6 only those residing in Northern Europe are included. Point estimates tend to increase further and the coefficient on Asia becomes significant, in addition to Europe and North America. The p-value on the F-test increases further to $31 \%$, indicating that the estimated coefficient become more similar. The pattern of heterogeneity across ancestry across continents in Table 6 mirrors the pattern in Table 5. When studying individuals in a broad set of countries there is heterogeneity across ancestry, but as the analysis narrows in on a more homogenous institutional environment with higher trust the heterogeneity dissipates.

\footnotetext{
${ }^{29}$ North America is the defined as the U.S. and Canada. Latin America includes Mexico and the countries in the Americas south thereof.
} 


\subsubsection{Individual Characteristics}

In this section I interact the trust level in the mother's country of birth with several individual characteristics. The purpose is to examine if transmission of trust differs across these dimension. The first two specifications consider measures of how integrated the second generation immigrants are. I interact an indicator of being a citizen with trust in the mother's country. The point estimates for those with and without citizenship are very similar as seen in model A in Table 7. Second generation immigrants are very integrated along this margin, 94\% are citizens of their birth country, which may explain the larger standard error on the term for not being a citizen. In model B I turn to a more informal measure of integration by focusing on if a second language is spoken at home. $38 \%$ of the sample speaks a second language at home, which yields a more even split of the sample between the interaction terms. The point estimate on the transmission is much higher for those who don't speak a second language at home. The test of equality of the coefficients does not reject at conventional levels.

The following two specifications split the sample by strength of the direct vertical transmission. In model C I split by age, with those above 40 years of age being less exposed to parental influences and more exposed to horizontal influences in the current society. The point estimate in model $\mathrm{C}$ in Table 7 for those less than 40 years old, and more closely connected to parental influences, is higher than for the older group. The results are consistent with the hypothesis but the difference is not statistically significant. The same finding holds when internet use is considered. Internet provides another channel of horizontal influence which may weaken the direct influence by parents. The point estimates support this story as the intergenerational influence is lower for those who use the internet at least once a week, as seen in model D in Table 7. The coefficients are, however, not significantly different.

The last two specifications examine if parental characteristics influence the transmission of trust. The effect of having a working father at age 14 is examined in model E in Table 7. The point estimate for having a working father is much higher compared to the transmission for those who don't, although the difference is not significant. ${ }^{30}$ In model $\mathrm{F}$ in Table $7 \mathrm{I}$ examine if the transmission of trust differs by the mother's education (when the child is age 14). The transmission coefficient is much higher for those who have a mother with upper secondary or tertiary education compared to those with a less educated mother. The difference is close to being significant with a p-value of $13.6 \%$.

\footnotetext{
${ }^{30}$ Having a father that does not work at age 14 includes two categories: fathers who didn't work (but were present) and fathers who weren't present. The data isn't rich enough to distinguish between the effects of these two categories.
} 


\subsection{Determinants of Ancestral Country Trust and Its Transmission}

So far the trust in the parent's country of birth has been taken as exogenous. In this section I study one factor that may shape the ancestral trust levels, and this factor is language. The idea is to examine if linguistic features have an influence on trust levels, and to estimate how the ancestral trust shifted by these "deep" features relates to the trust of second generation immigrants. I combine the approach of relating language structure to trust with the epidemiological approach and apply it to the cultural transmission of trust, which is new to the literature.

\subsubsection{Language}

The shifter of trust is language structure. Languages have features that put more or less emphasis on how to relate to other people. The structure of languages are stable and slow moving, arguably more so than cultural beliefs like trust.

One feature that differs across languages is the use of first and second pronouns in conversations. In Italian, for example, it's permissible to drop the pronoun while in English it's mandatory to use the pronoun. Languages that forbid dropping the first-person pronoun are typical of cultural traditions that gave more emphasis to the individual relative to his social context and thus were more respectful of the individual and his rights as argued by Kashima and Kashima $(1998,2005)$. Licht, Goldschmidt, and Schwartz (2007) used this grammatical rule to examine how individualism affects the rule of law. Tabellini (2008) use the rule to examine how trust affects institutions across countries. I follow Tabellini (2008) and define the variable "No pronoun drop" as 1 if the language forbids the drop of pronouns and 0 otherwise, and I expect it to be positively related to trust.

The second grammatical rule I consider, in keeping with Tabellini (2008), is the distinction between singular and plural personal pronouns. French, for example, differentiates between the singular and plural You, the Tu and Vous (T-V for short), depending on the social distance between the subjects. Many languages had the T-V distinction historically but later dropped it. Languages who kept the T-V distinction are indicative of cultures that put stronger emphasis on hierarchy and social distance, which may have a negative influence on generalized trust. The variable "2nd person differentiation" is defined as 1 if the number of second person pronouns that might be used in spoken language varies according to the social proximity between speakers and 0 otherwise. ${ }^{31}$ The variable is expected to have a negative relationship with trust.

\footnotetext{
${ }^{31}$ The variable distinguishes between languages that allow for $2^{\text {nd }}$ person differentiation compared to those that don't. The variable does not address if the differentiation is common in practice, where allowed, which may affect the accuracy of the variable. However, such mismeasurement would not invalidate the use of the variable, but rather only attenuate the relationship between language structure and trust.
} 
Based on these two variables capturing grammatical rules I define "Language" as No pronoun drop minus 2nd person differentiation. Language is expected to be positively related to trust. The variable is defined by country. For some countries with different language groups the variable is a weighted average of the respective language groups, where possible. ${ }^{32}$ The exact definitions follow Tabellini (2008), with one adjustment. ${ }^{33,34}$ The relationship between language structure and ancestral country trust is presented in Table 8. The estimated coefficient is positive and strongly significant. ${ }^{35}$ The positive sign is as expected; trust is higher in countries where the language puts more emphasis on the individual's rights, and less emphasis on hierarchy.

I use the language structure, as captured by the variable Language, in the parent's country of birth as a shifter of the trust in the parent's country of birth. ${ }^{36}$ The baseline result for second generation immigrants with an immigrant mother is presented in specification 1 in Table 9. The point estimate on trust in the mother's birth country is about double the magnitude compared to Table 1 and remains strongly significant in spite of the larger standard error. As the epidemiological approach has an attenuation bias built in using Language as an exogenous shifter may address the mismeasurement, which would lead to a higher estimate of the transmission of trust.

The estimates in Table 9 may be preferred to the baseline results if they address the measurement problem. This interpretation rests on the assumption that the ancestral country language structure has no direct effect on individual trust of the second generation immigrant. Since the child is born and reside in a different country where the vast majority speaks the language of their country of residence, there is no obvious link between the child's trust and the language structure of the ancestral country. Remaining concerns can, at least partially, be addressed.

I observe if the individual speaks a second language at home and what language that is, which indicates a link to another language. The first language spoken is also observed. In the second specification of Table 9 । control for the language structure of the first language spoken, and the estimate on ancestral trust is unchanged. In the third specification I also add the language structure of the second language spoken as well as an indicator of a second language being spoken at home. The transmission of trust is robust also to

\footnotetext{
${ }^{32}$ The weighting applies to Canada, Singapore, South Africa, and Switzerland.

${ }^{33}$ The data is generously made available at http://didattica.unibocconi.it/mypage/index.php? IdUte=48805\&idr=5112.

${ }^{34}$ I adjust the coding of Danish to allow for second person differentiation.

${ }^{35}$ The F-statistic for the exclusion of the Language variable is 19.

${ }^{36}$ Similar results are obtained if the Language variable is split in its two components, but the first stage is not quite as strong so the Language specification is preferred.
} 
this specification. The results rule out a direct effect of the languages the individual speak on his trust, while the influence of ancestral trust remains.

Since Licht, Goldschmidt, and Schwartz (2007) related no pronoun drop to individualism there is a potential concern that the language structure may affect the individualism of the second generation immigrant. The data includes a question that captures individualism by asking how important it is to be free and make your own decision. ${ }^{37}$ Controlling for this variable has no effect on the estimates. I conclude that there does not seem to be an effect on trust of language structure through individualism.

The estimates on the sample with an immigrant father are presented in specifications 4 through 6 of Table 9. The point estimates are double the magnitude of the baseline in Table 1, mirroring the results for the immigrant mother's sample. The positive point estimates are consistent with transmission of trust in the immigrant father sample. The standard errors are also larger and the estimates remain insignificant at conventional levels, which leave us with weaker evidence on the father's side.

As in all empirical analysis, the interpretation of the results depends on the assumptions imposed. The interpretation of the results in Table 9 as unbiased estimates that address the built in attenuation bias is conditional on the assumption that ancestral language structure has no direct effect on individual trust. There is of course no way to be certain the assumption is true but the robustness of the results when including the controls for the languages spoken by the individual provide some plausibility to the assumption.

\section{Conclusion}

Second generation immigrants are exogenously exposed to similar institutional environments in their countries of birth, yet they are influenced by different ancestral backgrounds based on where their parents were born. I use this to estimate the intergenerational transmission of trust through the influence of ancestral trust on individual trust. The broad set of countries the individuals live in and the diverse ancestral backgrounds allow a more comprehensive analysis of the cultural transmission of trust than present in the literature.

Trust is affected by current individual and institutional influences, as indicated by the significant individual controls and country fixed effects. However, part of trust is influenced by the cultural ancestry as captured by the effect of trust in the parent's country of birth. The influence from the parent's country is

\footnotetext{
${ }^{37}$ The question asks if the respondent is like or not like the person in the statement "It is important to her/him to make her/his own decisions about what she/he does. She/he likes to be free and not depend on others."
} 
quantitatively significant and it is of similar magnitude to individual influences such as increasing income from the bottom to the top three deciles of the income distribution.

The results provide insights of how immigrants are integrated into society. It matters where their ancestral roots are and where they reside. Trust may be more persistent among immigrants from more developed nations. In the Northern European context trust is persistent no matter the ancestry, while individuals may adapt quickly to trust levels in Southern Europe. ${ }^{38}$

Although the main reason for studying second generation immigrants is that it allows separating the cultural influence from institutions, there are also policy implications from this focus. As trust drives growth, the composition of immigrants may have long run effects on growth. It may also be a consideration when immigration policies are shaped. As trust affects the economic activity there are implications for fiscal budgets. Net present value computations of immigration such as Storesletten (2000) could be augmented to account for the transmission of trust. Such adjustments would, as the heterogeneity results suggest, depend on the specific context in which the immigrants enter.

\section{References}

Alesina, Alberto, and Eliana La Ferrara (2002). "Who trusts others?" Journal of Public Economics, 85, 207234.

Alesina, Alberto, and Paola Giuliano (2010). "The Power of the Family." Journal of Economic Growth, 15(2): 93-125.

Alesina, Alberto, and Paola Giuliano (2011). "Family Ties and Political Participation." Journal of the European Economic Association, Volume 9, Issue 5, pages 817-839.

Algan, Yann, and Pierre Cahuc (2010). "Inherited Trust and Growth." American Economic Review, 100(5): 2060--92.

Berggren, Niclas, and Christian Bjørnskov (2011). "Is the importance of religion in daily life related to social trust? Cross-country and cross-state comparisons." Journal of Economic Behavior and Organization, 80: 459-480.

Berggren, Niclas och Jordahl, Henrik (2006). "Free to Trust: Economic Freedom and Social Capital." Kyklos, 59(2): 141-169.

Bergh, Andreas and Christian Bjørnskov. 2011. "Historical trust levels predict the current size if the welfare state." Kyklos 64:1-19.

Bisin, Alberto, and Thierry Verdier (2001). "The Economics of Cultural Transmission and the Dynamics of Preferences." Journal of Economic Theory 97, 298-319.

Butler, Jeffrey, Paola Giuliano, and Luigi Guiso (2011). "The Right Amount of Trust." Working paper, UCLA.

Dinesen, Peter Thisted (2011). "Where You Come From or Where You Live? Examining the Cultural and Institutional Explanation of Generalized Trust Using Migration as a Natural Experiment." European Sociological Review (advance access).

\footnotetext{
${ }^{38}$ Trust levels of second generation immigrants are on average similar to trust levels of natives.
} 
Dohmen, Thomas, Armin Falk, David Huffman, Uwe Sunde (2011). "The Intergenerational Transmission of Risk and Trust Attitudes." Forthcoming in the Review of Economic Studies.

Fernandez, Raquel (2010). "Does Culture Matter?" Handbook of Social Economics, Jess Benhabib, Alberto Bisin, Matt Jackson, eds., North-Holland.

Fernández, Raquel, and Alessandra Fogli. 2006. "Fertility: The Role of Culture and Family Experience." Journal of the European Economic Association, 4(2-3): 552-61.

Fernández, Raquel, and Alessandra Fogli. 2009. "Culture: An Empirical Investigation of Beliefs, Work, and Fertility." American Economic Journal: Macroeconomics, 1(1): 146-77.

Guinnane, Timothy W., Carolyn M. Moehling, and Cormac Ó Gráda. 2006. "The Fertility of the Irish in the United States in 1910." Explorations in Economic History, 43(3): 465-85.

Guiso, Luigi, Paola Sapienza and Luigi Zingales (2006), "Does Culture Affect Economic Outcomes?" Journal of Economic Perspectives, Vol. 20, No. 2, pp. 23-48.

Guiso, Luigi, Paola Sapienza, and Luigi Zingales (2008). "Long Term Persistence." University of Chicago Graduate School of Business Working Paper 08-11.

Kashima, Emiko S., and Yoshihisa Kashima (1998). "Culture and Language: The Case of Cultural Dimensions and Personal Pronoun Use." Journal of Cross-Cultural Psychology, 29(3), 461-486.

Kashima, Emiko S., and Yoshihisa Kashima (2005). "Erratum to Kashima and Kashima (1998) and Reiteration." Journal of Cross-Cultural Psychology, 36 (3) 396-400.

Knack, Stephen, and Philip Keefer (1997). "Does Social Capital Have an Economic Pay-Off? A Cross Country Investigation." Quarterly Journal of Economics, 112(4), 1251-1288.

Kumlin, Staffan and Bo Rothstein. (2005). "Making and Breaking Social Capital: The Impact of Welfare-

State Institutions." Comparative Political Studies. 38: 339-365.

La Porta R., F. Lopez-De-Silanes, A. Schleifer and R.Vishny (1999), "The quality of Government", The Journal of Law, Economics and Organization, 15:222-79.

La Porta, Rafeal, Florencio Lopez-de-Silanes, Andrei Shleifer, and Robert W. Vishny (1997). "Trust in Large Organizations." American Economic Review, 87(2), 333-338.

Licht, Amir N., Chanan Goldschmidt, and Shalom H. Schwartz (2007). "Culture Rules: The Foundations of the Rule of Law and Other Norms of Governance." Journal of Comparative Economics, 35(4), 659-688.

Luttmer, Erzo and Monica Singhal (2011). "Culture, Context, and the Taste for Redistribution", American Economic Journal: Economic Policy, 3(1), pp. 157-179.

Nunn, Nathan and Leonard Wantchekon (2011). "The Slave Trade and the Origins of Mistrust in Africa." Forthcoming in the American Economic Review.

Storesletten, Kjetil (2000). "Sustaining Fiscal Policy Through Immigration." Journal of Political Economy, vol. 108 (2), pp. 300-23.

Tabellini, Guido (2008). "Institutions and Culture." Journal of the European Economic Association Papers and Proceedings, Vol.6(2-3).

Tabellini, Guido (2010). "Culture and institutions: economic development in the regions of Europe." Journal of the European Economic Association, 8(4):677-716.

Uslaner, Eric M. (2002). "The Moral Foundations of Trust." Cambridge University Press.

Uslaner, Eric M. (2008). "WHERE YOU STAND DEPENDS UPON WHERE YOUR GRANDPARENTS SAT. THE INHERITABILITY OF GENERALIZED TRUST." Public Opinion Quarterly, Vol. 72, No. 4, Winter 2008, pp. 725-740. 


\section{Tables}

Table 1. Effects of Trust in Parent's Birth Country on Children's Trust.

\begin{tabular}{|c|c|c|c|c|}
\hline Dependent variable: Trust & $\begin{array}{l}\text { Immigrant } \\
\text { mother } \\
(1)\end{array}$ & $\begin{array}{l}\text { Immigrant } \\
\text { mother } \\
(2)\end{array}$ & $\begin{array}{l}\text { Immigrant } \\
\text { father } \\
\text { (3) }\end{array}$ & $\begin{array}{l}\text { Immigrant } \\
\text { father } \\
\text { (4) }\end{array}$ \\
\hline Trust, mother's birth country & $\begin{array}{c}1.073 \\
(0.474)^{* *}\end{array}$ & $\begin{array}{c}0.984 \\
(0.414)^{* *}\end{array}$ & & \\
\hline Trust, father's birth country & & & $\begin{array}{c}0.355 \\
(0.556)\end{array}$ & $\begin{array}{c}0.274 \\
(0.486)\end{array}$ \\
\hline Age & $\begin{array}{c}0.003 \\
(0.009)\end{array}$ & $\begin{array}{c}-0.022 \\
(0.011)^{*}\end{array}$ & $\begin{array}{l}-0.004 \\
(0.007)\end{array}$ & $\begin{array}{c}-0.024 \\
(0.012)^{* *}\end{array}$ \\
\hline Age squared/100 & $\begin{array}{l}-0.003 \\
(0.011)\end{array}$ & $\begin{array}{c}0.026 \\
(0.011)^{* *}\end{array}$ & $\begin{array}{c}0.004 \\
(0.007)\end{array}$ & $\begin{array}{c}0.026 \\
(0.012)^{* *}\end{array}$ \\
\hline Female & $\begin{array}{l}-0.055 \\
(0.044)\end{array}$ & $\begin{array}{l}-0.009 \\
(0.052)\end{array}$ & $\begin{array}{l}-0.008 \\
(0.055)\end{array}$ & $\begin{array}{l}-0.026 \\
(0.052)\end{array}$ \\
\hline Married & & $\begin{array}{c}0.180 \\
(0.074)^{* *}\end{array}$ & & $\begin{array}{c}0.035 \\
(0.072)\end{array}$ \\
\hline Never married & & $\begin{array}{c}0.221 \\
(0.125)^{*}\end{array}$ & & $\begin{array}{c}0.027 \\
(0.119)\end{array}$ \\
\hline Upper secondary & & $\begin{array}{c}0.357 \\
(0.086)^{* * *}\end{array}$ & & $\begin{array}{c}0.246 \\
(0.092)^{* * *}\end{array}$ \\
\hline $\begin{array}{l}\text { College or } \\
\text { university }\end{array}$ & & $\begin{array}{c}0.903 \\
(0.091)^{* * *}\end{array}$ & & $\begin{array}{c}0.959 \\
(0.100)^{* * *}\end{array}$ \\
\hline Out of the labor force & & $\begin{array}{c}-0.157 \\
(0.079)^{* *}\end{array}$ & & $\begin{array}{l}-0.055 \\
(0.061)\end{array}$ \\
\hline Unemployed & & $\begin{array}{c}-0.419 \\
(0.141)^{* * *}\end{array}$ & & $\begin{array}{c}-0.350 \\
(0.182)^{*}\end{array}$ \\
\hline Low income & & $\begin{array}{c}-0.194 \\
(0.078)^{* *}\end{array}$ & & $\begin{array}{c}-0.148 \\
(0.081)^{*}\end{array}$ \\
\hline Middle income & & $\begin{array}{c}0.013 \\
(0.049)\end{array}$ & & $\begin{array}{l}-0.006 \\
(0.056)\end{array}$ \\
\hline Catholic & & $\begin{array}{c}-0.081 \\
(0.079)\end{array}$ & & $\begin{array}{l}-0.039 \\
(0.098)\end{array}$ \\
\hline Protestant & & $\begin{array}{c}0.277 \\
(0.084)^{* * *}\end{array}$ & & $\begin{array}{c}0.142 \\
(0.102)\end{array}$ \\
\hline Orthodox & & $\begin{array}{c}0.123 \\
(0.169)\end{array}$ & & $\begin{array}{c}0.130 \\
(0.105)\end{array}$ \\
\hline R-squared & 0.107 & 0.127 & 0.098 & 0.117 \\
\hline Observations & 7510 & 7235 & 7843 & 7535 \\
\hline
\end{tabular}

Notes: Trust is coded from 0 , can't be too careful, to 10 , most people can be trusted.

All regressions include a full set of country of residence-by-year fixed effects.

Standard errors, in parenthesis, are clustered by parent's birth country,

$* p<0.1,{ }^{* *} p<0.05, * * * p<0.01$. 
Table 2. Effects of Trust Accounting for Country Characteristics.

\begin{tabular}{|c|c|c|c|c|}
\hline \multicolumn{5}{|l|}{ Dependent variable: Trust } \\
\hline Sample: & $\begin{array}{l}\text { Immigrant } \\
\text { mother } \\
(1)\end{array}$ & $\begin{array}{l}\text { Immigrant } \\
\text { mother } \\
(2)\end{array}$ & $\begin{array}{c}\text { Immigrant } \\
\text { father } \\
(3)\end{array}$ & $\begin{array}{c}\text { Immigrant } \\
\text { father } \\
(4)\end{array}$ \\
\hline \multirow[t]{2}{*}{ Trust, mother's birth country } & 1.017 & 1.030 & & \\
\hline & $(0.400)^{* *}$ & $(0.403)^{* *}$ & & \\
\hline \multirow[t]{2}{*}{ Trust, father's birth country } & & & 0.545 & 0.627 \\
\hline & & & $(0.450)$ & $(0.448)$ \\
\hline \multirow[t]{2}{*}{$\log (g d p)$, mother's birth country } & 0.108 & 0.099 & & \\
\hline & $(0.043)^{* *}$ & $(0.056)^{*}$ & & \\
\hline \multirow[t]{2}{*}{ Polity2, mother's birth country } & & 0.001 & & \\
\hline & & $(0.007)$ & & \\
\hline \multirow[t]{2}{*}{$\log (g d p)$, father's birth country } & & & 0.049 & -0.015 \\
\hline & & & $(0.040)$ & (0.038) \\
\hline \multirow[t]{2}{*}{ Polity2, father's birth country } & & & & 0.015 \\
\hline & & & & $(0.008)^{*}$ \\
\hline Individual controls & Yes & Yes & Yes & Yes \\
\hline Country-by-year fixed effects & Yes & Yes & Yes & Yes \\
\hline R-squared & 0.135 & 0.132 & 0.121 & 0.120 \\
\hline Observations & 6829 & 6738 & 7039 & 6954 \\
\hline
\end{tabular}

Notes: Trust is coded from 0 , can't be too careful, to 10 , most people can be trusted.

Individual controls include age and its square, gender, marital status, education, employment status, income, and religion. All regressions include a full set of country of residence fixed effects.

Standard errors, in parenthesis, are clustered by parent's birth country, ${ }^{*} p<0.1,{ }^{* *} p<0.05,{ }^{* * *} p<0.01$. 
Table 3. Effects of Trust in Parent's Birth Country Conditional on Parental Education.

\begin{tabular}{|c|c|c|c|c|c|c|}
\hline $\begin{array}{l}\text { Dependent variable: Irust } \\
\text { Sample: }\end{array}$ & $\begin{array}{l}\text { Immigrant } \\
\text { mother } \\
\text { (1) }\end{array}$ & $\begin{array}{l}\text { Immigrant } \\
\text { mother } \\
(2)\end{array}$ & $\begin{array}{l}\text { Immigrant } \\
\text { mother } \\
(3)\end{array}$ & $\begin{array}{c}\text { Immigrant } \\
\text { father } \\
\text { (4) }\end{array}$ & $\begin{array}{l}\text { Immigrant } \\
\text { father } \\
\text { (5) }\end{array}$ & $\begin{array}{c}\text { Immigrant } \\
\text { father } \\
\text { (6) }\end{array}$ \\
\hline Trust, mother's birth country & $\begin{array}{c}0.864 \\
(0.397)^{* *}\end{array}$ & $\begin{array}{c}0.857 \\
(0.398)^{* *}\end{array}$ & $\begin{array}{c}0.834 \\
(0.388)^{* *}\end{array}$ & & & \\
\hline Trust, father's birth country & & & & $\begin{array}{c}0.198 \\
(0.458)\end{array}$ & $\begin{array}{c}0.207 \\
(0.456)\end{array}$ & $\begin{array}{c}0.144 \\
(0.442)\end{array}$ \\
\hline $\begin{array}{l}\text { Upper secondary education, } \\
\text { mother }\end{array}$ & $\begin{array}{c}0.196 \\
(0.069)^{* * *}\end{array}$ & $\begin{array}{c}0.188 \\
(0.070)^{* * *}\end{array}$ & $\begin{array}{c}0.092 \\
(0.089)\end{array}$ & & & $\begin{array}{c}0.270 \\
(0.074)^{* * *}\end{array}$ \\
\hline Tertiary education, mother & $\begin{array}{c}0.434 \\
(0.094)^{* * *}\end{array}$ & $\begin{array}{c}0.421 \\
(0.094)^{* * *}\end{array}$ & $\begin{array}{c}0.316 \\
(0.124)^{* *}\end{array}$ & & & $\begin{array}{c}0.327 \\
(0.114)^{* * *}\end{array}$ \\
\hline $\begin{array}{l}\text { Mother working } \\
\text { (when indivividual age 14) }\end{array}$ & & $\begin{array}{c}0.057 \\
(0.045)\end{array}$ & & & & \\
\hline Upper secondary education, fa & ther & & $\begin{array}{c}0.224 \\
(0.088)^{* *}\end{array}$ & $\begin{array}{c}0.121 \\
(0.051)^{* *}\end{array}$ & $\begin{array}{c}0.086 \\
(0.052)\end{array}$ & $\begin{array}{c}0.023 \\
(0.047)\end{array}$ \\
\hline Tertiary education, father & & & $\begin{array}{c}0.230 \\
(0.114)^{* *}\end{array}$ & $\begin{array}{c}0.432 \\
(0.087)^{* * *}\end{array}$ & $\begin{array}{c}0.395 \\
(0.088)^{* * *}\end{array}$ & $\begin{array}{c}0.263 \\
(0.113)^{* *}\end{array}$ \\
\hline $\begin{array}{l}\text { Father working } \\
\text { (when individual age 14) }\end{array}$ & & & & & $\begin{array}{c}0.306 \\
(0.065)^{* * *}\end{array}$ & \\
\hline Individual controls & Yes & Yes & Yes & Yes & Yes & Yes \\
\hline Country-by-year fixed effects & Yes & Yes & Yes & Yes & Yes & Yes \\
\hline R-squared & 0.129 & 0.129 & 0.130 & 0.119 & 0.121 & 0.120 \\
\hline Observations & 7235 & 7235 & 7235 & 7535 & 7535 & 7535 \\
\hline
\end{tabular}

Notes: Trust is coded from 0 , can't be too careful, to 10 , most people can be trusted.

Individual controls include age and its square, gender, marital status, education, employment status, income, and religion. All regressions include a full set of country of residence fixed effects.

Standard errors, in parenthesis, are clustered by parent's birth country, ${ }^{*} p<0.1,{ }^{* *} p<0.05,{ }^{* * *} p<0.01$. 
Table 4. Heterogeneity Based on Birth Place of 2nd Generation Immigrant.

\begin{tabular}{|c|c|c|c|c|c|}
\hline \multirow[b]{2}{*}{ Model } & \multirow[b]{2}{*}{ Sample } & \multicolumn{4}{|c|}{ Main sample: Second generation immigrants with an immigrant mother } \\
\hline & & Dependent variable: Trust & $\begin{array}{c}\text { Coefficient } \\
\text { (s.e.) }\end{array}$ & $\begin{array}{c}\text { Test of } \\
\text { equality } \\
\text { (p-value) }\end{array}$ & Observations \\
\hline \multirow[t]{4}{*}{ A } & Full & Trust, mother's birth country & 1.493 & 0.411 & 7235 \\
\hline & Sample & *Born in Western Europe & $(0.417)^{* * *}$ & & \\
\hline & & Trust, mother's birth country & 0.284 & & \\
\hline & & *Born in Eastern Europe & $(1.405)$ & & \\
\hline \multirow[t]{6}{*}{ B } & Full & Trust, mother's birth country & 1.809 & 0.006 & 7235 \\
\hline & Sample & *Born in Northern Europe & $(0.484)^{* * *}$ & & \\
\hline & & Trust, mother's birth country & -0.497 & & \\
\hline & & *Born in Southern Europe & (0.515) & & \\
\hline & & Trust, mother's birth country & 0.273 & & \\
\hline & & *Born in Eastern Europe & (1.404) & & \\
\hline \multirow[t]{4}{*}{ C } & Western & Trust, mother's birth country & 1.674 & 0.0016 & 5395 \\
\hline & Europe & *Born in Northern Europe & $(0.465)^{* * *}$ & & \\
\hline & born & Trust, mother's birth country & -0.573 & & \\
\hline & & *Born in Southern Europe & $(0.523)$ & & \\
\hline
\end{tabular}

Note: Sample refers to the country of birth and residence of the 2 nd generation immigrant.

Estimated coefficients on trust in the mother's country of birth interacted with an indicator of the

birth/residence country of the 2 nd generation immigrant is reported.

The $p$-value refers to a F-test of equality of the reported coefficients, by model.

All regressions include the full set of individual controls and country-by-year fixed effects as in Table 1.

Standard errors, in parenthesis, are clustered by parent's birth country, ${ }^{*} p<0.1,{ }^{* *} p<0.05,{ }^{* * *} p<0.01$. 
Table 5. Heterogeneity Based on Ancestry (Western Europe).

\begin{tabular}{|c|c|c|c|c|c|}
\hline Model & Sample & Dependent variable: Trust & $\begin{array}{c}\text { Coefficient } \\
\text { (s.e.) }\end{array}$ & $\begin{array}{l}\text { Test of } \\
\text { equality } \\
\text { (p-value) }\end{array}$ & Observations \\
\hline$A$ & $\begin{array}{c}\text { Full } \\
\text { Sample }\end{array}$ & $\begin{array}{l}\text { Trust, mother's birth country } \\
{ }^{*} \text { Mother from Western Europe } \\
\text { Trust, mother's birth country } \\
\text { *Mother not from Western Europe }\end{array}$ & $\begin{array}{c}1.018 \\
(0.397)^{* *} \\
0.587 \\
(0.577)\end{array}$ & 0.221 & 7188 \\
\hline B & $\begin{array}{l}\text { Western } \\
\text { Europe } \\
\text { born }\end{array}$ & $\begin{array}{l}\text { Trust, mother's birth country } \\
\text { *Mother from Western Europe } \\
\text { Trust, mother's birth country } \\
\text { *Mother not from Western Europe }\end{array}$ & $\begin{array}{c}1.350 \\
(0.406)^{* * *} \\
1.136 \\
(0.514)^{* *}\end{array}$ & 0.483 & 4128 \\
\hline C & $\begin{array}{c}\text { Northern } \\
\text { Europe } \\
\text { born }\end{array}$ & $\begin{array}{l}\text { Trust, mother's birth country } \\
{ }^{*} \text { Mother from Western Europe } \\
\text { Trust, mother's birth country } \\
\text { *Mother not from Western Europe }\end{array}$ & $\begin{array}{c}1.617 \\
(0.469)^{* * *} \\
1.502 \\
(0.592)^{* *}\end{array}$ & 0.714 & 3178 \\
\hline
\end{tabular}

Note: Sample refers to the country of birth and residence of the 2 nd generation immigrant.

Estimated coefficients on trust in the mother's country of birth interacted with an indicator of the birth/residence country of the 2 nd generation immigrant is reported.

The $p$-value refers to a F-test of equality of the reported coefficients, by model.

All regressions include the full set of individual controls and country-by-year fixed effects as in Table 1. Standard errors, in parenthesis, are clustered by parent's birth country, ${ }^{*} p<0.1,{ }^{* *} p<0.05,{ }^{* * *} p<0.01$. 
Table 6. Heterogeneity Based on Ancestry (5 Continents).

\begin{tabular}{|c|c|c|c|c|c|}
\hline Model & Sample & Dependent variable: Trust & $\begin{array}{c}\text { Coefficient } \\
\text { (s.e.) }\end{array}$ & $\begin{array}{c}\text { Test of } \\
\text { equality } \\
\text { (p-value) }\end{array}$ & Observations \\
\hline$A$ & $\begin{array}{c}\text { Full } \\
\text { Sample }\end{array}$ & $\begin{array}{l}\text { Trust, mother's birth country } \\
\text { *Mother from Europe } \\
\text { Trust, mother's birth country } \\
\text { *Mother from North America } \\
\text { Trust, mother's birth country } \\
\text { *Mother from Latin America } \\
\text { Trust, mother's birth country } \\
\text { *Mother from Africa } \\
\text { Trust, mother's birth country } \\
\text { *Mother from Asia }\end{array}$ & $\begin{array}{c}1.276 \\
(0.365)^{* * *} \\
1.224 \\
(0.307)^{* * *} \\
1.317 \\
(1.665) \\
0.449 \\
(0.526) \\
0.031 \\
(0.500)\end{array}$ & 0.037 & 7188 \\
\hline B & $\begin{array}{c}\text { Western } \\
\text { Europe } \\
\text { born }\end{array}$ & $\begin{array}{l}\text { Trust, mother's birth country } \\
\text { *Mother from Europe } \\
\text { Trust, mother's birth country } \\
\text { *Mother from North America } \\
\text { Trust, mother's birth country } \\
\text { *Mother from Latin America } \\
\text { Trust, mother's birth country } \\
\text { *Mother from Africa } \\
\text { Trust, mother's birth country } \\
\text { *Mother from Asia }\end{array}$ & $\begin{array}{c}1.375 \\
(0.421)^{* * *} \\
1.714 \\
(0.434)^{* * *} \\
2.034 \\
(1.538) \\
0.540 \\
(0.754) \\
0.882 \\
(0.542)\end{array}$ & 0.204 & 4128 \\
\hline C & $\begin{array}{c}\text { Northern } \\
\text { Europe } \\
\text { born }\end{array}$ & $\begin{array}{l}\text { Trust, mother's birth country } \\
\text { *Mother from Europe } \\
\text { Trust, mother's birth country } \\
\text { *Mother from North America } \\
\text { Trust, mother's birth country } \\
\text { *Mother from Latin America } \\
\text { Trust, mother's birth country } \\
\text { *Mother from Africa } \\
\text { Trust, mother's birth country } \\
\text { *Mother from Asia }\end{array}$ & $\begin{array}{c}1.619 \\
(0.473)^{* * *} \\
1.798 \\
(0.534)^{* * *} \\
2.379 \\
(1.566) \\
0.430 \\
(0.855) \\
1.085 \\
(0.582)^{*} \\
\end{array}$ & 0.31 & 3178 \\
\hline
\end{tabular}

Note: Sample refers to the country of birth and residence of the 2 nd generation immigrant.

Estimated coefficients on trust in the mother's country of birth interacted with an indicator of the birth/residence country of the 2 nd generation immigrant is reported.

The $p$-value of a F-test of equality of the reported coefficients, by model, is presented.

All regressions include the full set of individual controls and country-by-year fixed effects as in Table 1. Standard errors, in parenthesis, are clustered by parent's birth country, ${ }^{*} p<0.1,{ }^{* *} p<0.05,{ }^{* * *} p<0.01$. 
Table 7. Heterogeneity Based on Individual Characteristics.

\begin{tabular}{|c|c|c|c|c|c|}
\hline Model & Interaction & Dependent variable: Trust & $\begin{array}{c}\text { Coefficient } \\
\text { (s.e.) }\end{array}$ & $\begin{array}{c}\text { Test of } \\
\text { equality } \\
\text { (p-value) }\end{array}$ & Observations \\
\hline A & Citizenship & $\begin{array}{l}\text { Trust, mother's birth country } \\
{ }^{*} \text { Citizen of birth country } \\
\text { Trust, mother's birth country } \\
{ }^{*} \text { Not citizen of birth country }\end{array}$ & $\begin{array}{c}0.937 \\
(0.410)^{* *} \\
1.035 \\
(0.971)\end{array}$ & 0.918 & 7235 \\
\hline B & $\begin{array}{l}\text { Second } \\
\text { language } \\
\text { spoken } \\
\text { at home }\end{array}$ & $\begin{array}{l}\text { Trust, mother's birth country } \\
{ }^{*} \text { No second language at home } \\
\text { Trust, mother's birth country } \\
\text { *Second language at home }\end{array}$ & $\begin{array}{c}1.348 \\
(0.345)^{* * *} \\
0.514 \\
(0.604)\end{array}$ & 0.116 & 7235 \\
\hline C & Age & $\begin{array}{l}\text { Trust, mother's birth country } \\
\text { *Less than } 40 \text { years old } \\
\text { Trust, mother's birth country } \\
\text { *40 years or older }\end{array}$ & $\begin{array}{c}1.096 \\
(0.478)^{* *} \\
0.889 \\
(0.556)\end{array}$ & 0.739 & 7235 \\
\hline D & $\begin{array}{l}\text { Internet } \\
\text { use }\end{array}$ & $\begin{array}{l}\text { Trust, mother's birth country } \\
\text { *Use Internet frequently } \\
\text { Trust, mother's birth country } \\
\text { *Don't use internet frequently }\end{array}$ & $\begin{array}{c}0.797 \\
(0.465)^{*} \\
1.154 \\
(0.484)^{* *}\end{array}$ & 0.485 & 7235 \\
\hline $\mathrm{E}$ & $\begin{array}{l}\text { Father } \\
\text { working } \\
\text { at age } 14\end{array}$ & $\begin{array}{l}\text { Trust, mother's birth country } \\
\text { *Father working } \\
\text { Trust, mother's birth country } \\
\text { *Father not working or not present }\end{array}$ & $\begin{array}{c}1.065 \\
(0.426)^{* *} \\
0.401 \\
(0.756)\end{array}$ & 0.385 & 7235 \\
\hline $\mathrm{F}$ & $\begin{array}{l}\text { Mother's } \\
\text { education }\end{array}$ & $\begin{array}{l}\text { Trust, mother's birth country } \\
\text { *Mother with higher education } \\
\text { Trust, mother's birth country } \\
\text { *Mother with lower education }\end{array}$ & $\begin{array}{c}1.456 \\
(0.431)^{* * *} \\
0.674 \\
(0.469) \\
\end{array}$ & 0.136 & 7235 \\
\hline
\end{tabular}

Note: Sample refers to the country of birth and residence of the 2 nd generation immigrant.

Estimated coefficients on trust in the mother's country of birth interacted with an indicator of the birth/residence country of the 2 nd generation immigrant is reported.

The p-value of a F-test of equality of the reported coefficients, by model, is presented.

All regressions include the full set of individual controls and country-by-year fixed effects as in Table 1. Standard errors, in parenthesis, are clustered by parent's birth country, ${ }^{*} p<0.1,{ }^{* *} p<0.05,{ }^{* * *} p<0.01$. 
Table 8. Ancestral Trust on Language Structure.

\begin{tabular}{|c|c|c|c|c|c|c|}
\hline \multicolumn{7}{|c|}{ Dependent variable: Trust in the mother's or father's country of birth } \\
\hline Sample: & $\begin{array}{l}\text { Immigrant } \\
\text { mother } \\
\text { (1) }\end{array}$ & $\begin{array}{l}\text { Immigrant } \\
\text { mother } \\
\text { (2) }\end{array}$ & $\begin{array}{l}\text { Immigrant } \\
\text { mother } \\
\text { (3) }\end{array}$ & $\begin{array}{l}\text { Immigrant } \\
\text { father } \\
\text { (4) }\end{array}$ & $\begin{array}{l}\text { Immigrant } \\
\text { father } \\
\text { (5) }\end{array}$ & $\begin{array}{l}\text { Immigrant } \\
\text { father } \\
\text { (6) }\end{array}$ \\
\hline $\begin{array}{l}\text { Language structure, } \\
\text { mother's birth country }\end{array}$ & $\begin{array}{c}0.073 \\
(0.017)^{* * *}\end{array}$ & $\begin{array}{c}0.074 \\
(0.016)^{* * *}\end{array}$ & $\begin{array}{c}0.072 \\
(0.015)^{* * *}\end{array}$ & & & \\
\hline $\begin{array}{l}\text { Language structure, } \\
\text { father's birth country }\end{array}$ & & & & $\begin{array}{c}0.068 \\
(0.017)^{* * *}\end{array}$ & $\begin{array}{c}0.068 \\
(0.016)^{* * *}\end{array}$ & $\begin{array}{c}0.066 \\
(0.016)^{* * *}\end{array}$ \\
\hline Individual controls & Yes & Yes & Yes & Yes & Yes & Yes \\
\hline Country-by-year fixed effects & Yes & Yes & Yes & Yes & Yes & Yes \\
\hline Observations & 5957 & 5470 & 5470 & 6083 & 5544 & 5544 \\
\hline
\end{tabular}

Notes: All regressions include a full set of country of residence-by-year fixed effects.

Individual controls include age and its square, gender, marital status, education, employment status, income, and religion. Standard errors, in parenthesis, are clustered by parent's birth country, ${ }^{*} p<0.1,{ }^{* *} p<0.05,{ }^{* * *} p<0.01$.

Table 9. Language Structure as Exogenous Shifter Ancestral of Trust.

\begin{tabular}{lcccccc}
\hline $\begin{array}{l}\text { Dependent variable: Trust } \\
\text { Sample: }\end{array}$ & $\begin{array}{c}\text { Immigrant } \\
\text { mother } \\
(1)\end{array}$ & $\begin{array}{c}\text { Immigrant } \\
\text { mother } \\
(2)\end{array}$ & $\begin{array}{c}\text { Immigrant } \\
\text { mother } \\
(3)\end{array}$ & $\begin{array}{c}\text { Immigrant } \\
\text { father } \\
(4)\end{array}$ & $\begin{array}{c}\text { Immigrant } \\
\text { father } \\
(5)\end{array}$ & $\begin{array}{c}\text { Immigrant } \\
\text { father } \\
(6)\end{array}$ \\
\hline Trust, mother's birth country & 3.051 & 2.982 & 2.687 & & & \\
& $(1.119)^{* * *}$ & $(1.129)^{* * *}$ & $(1.125)^{* *}$ & & & \\
Trust, father's birth country & & & & 1.508 & 1.052 & 0.458 \\
& & & & $(0.978)$ & $(0.981)$ & $(0.906)$ \\
Language structure, 1st & & -0.023 & 0.003 & & 0.073 & 0.127 \\
language spoken at home & & $(0.087)$ & $(0.09)$ & & $(0.085)$ & $(0.074)^{*}$ \\
Language structure, 2nd & & & 0.135 & & & 0.295 \\
language spoken at home & & & $(0.121)$ & & & $(0.096)^{* * *}$ \\
No second language & & & 0.034 & & & -0.038 \\
spoken at home & & & $(0.100)$ & & & $(0.103)$ \\
& Yes & Yes & Yes & Yes & Yes & Yes \\
Individual controls & Yes & Yes & Yes & Yes & Yes & Yes \\
Country-by-year fixed effects & & & & & & \\
& 5957 & 5470 & 5470 & 6083 & 5544 & 5544 \\
\hline Observations & & & & &
\end{tabular}

Notes: Trust is coded from 0 , can't be too careful, to 10 , most people can be trusted.

Language structure in parent's birth country used as a shifter for trust in parent's birth country.

Individual controls include age and its square, gender, marital status, education, employment status, income, and religion. All regressions include a full set of country of residence-by-year fixed effects.

Standard errors, in parenthesis, are clustered by parent's birth country, ${ }^{*} p<0.1, * * p<0.05,{ }^{* * *} p<0.01$. 


\section{Appendix Tables}

Table A1. Summary statistics.

\begin{tabular}{lcccccccc}
\hline & \multicolumn{7}{c}{ Immigrant mother sample } & \multicolumn{5}{c}{ Immigrant father sample } \\
& Mean & Std. Dev. & Min & Max & Mean & Std. Dev. & Min & Max \\
\hline Variable & 4.91 & 2.49 & 0 & 10 & 4.86 & 2.48 & 0 & 10 \\
Trust & .291 & .111 & 0.06 & 0.66 & 0.284 & 0.105 & 0.05 & 0.66 \\
Age & 43.2 & 17.9 & 14 & 98 & 42.9 & 17.8 & 15 & 96 \\
Woman & .537 & .499 & 0 & 1 & 0.537 & 0.499 & 0 & 1 \\
Married & .488 & .5 & 0 & 1 & 0.489 & 0.500 & 0 & 1 \\
& & & & & & & & \\
Never married & .334 & .472 & 0 & 1 & 0.337 & 0.473 & 0 & 1 \\
Upper Secondary education birth country & .345 & .475 & 0 & 1 & 0.341 & 0.474 & 0 & 1 \\
University education & .226 & .418 & 0 & 1 & 0.223 & 0.416 & 0 & 1 \\
Out of labor force & .443 & .497 & 0 & 1 & 0.442 & 0.497 & 0 & 1 \\
Unemployed & .044 & .206 & 0 & 1 & 0.046 & 0.209 & 0 & 1 \\
& & & & & & & & \\
Low income & .224 & .417 & 0 & 1 & 0.226 & 0.418 & 0 & 1 \\
Middle income & .297 & .457 & 0 & 1 & 0.293 & 0.455 & 0 & 1 \\
Catholic & .192 & .394 & 0 & 1 & 0.176 & 0.381 & 0 & 1 \\
Protestant & .068 & .252 & 0 & 1 & 0.063 & 0.243 & 0 & 1 \\
Orthodox & .093 & .291 & 0 & 1 & 0.099 & 0.299 & 0 & 1 \\
Upper Secondary, parent & .195 & .396 & 0 & 1 & 0.209 & 0.407 & 0 & 1 \\
University education, parent & .104 & .306 & 0 & 1 & 0.134 & 0.340 & 0 & 1 \\
Working Parent, at age 14 & .56 & .496 & 0 & 1 & 0.841 & 0.366 & 0 & 1 \\
\hline
\end{tabular}


Table A2. Countries Participating in the ESS by Survey Round.

\begin{tabular}{|c|c|c|c|c|c|c|c|c|}
\hline \multirow{2}{*}{ Country } & \multicolumn{5}{|c|}{ Survey Round: } & \multirow{2}{*}{$\begin{array}{c}\text { Northern } \\
\text { Europe }\end{array}$} & \multirow{2}{*}{$\begin{array}{c}\text { Southern } \\
\text { Europe }\end{array}$} & \multirow{2}{*}{$\begin{array}{l}\text { Eastern } \\
\text { Europe }\end{array}$} \\
\hline & 1 & 2 & 3 & 4 & 5 & & & \\
\hline Austria & $x$ & $x$ & $x$ & & & 1 & & \\
\hline Belgium & $x$ & $x$ & $x$ & $x$ & $x$ & 1 & & \\
\hline Bulgaria & & & $x$ & $x$ & $x$ & & & 1 \\
\hline Cyprus & & & $x$ & $x$ & & & 1 & \\
\hline Czech Republic & $x$ & $x$ & & $x$ & $x$ & & & 1 \\
\hline Denmark & $x$ & $x$ & $x$ & $x$ & $x$ & 1 & & \\
\hline Estonia & & $x$ & $x$ & $x$ & $x$ & & & 1 \\
\hline Finland & $x$ & $x$ & $x$ & $x$ & $x$ & 1 & & \\
\hline France & $x$ & $x$ & $x$ & $x$ & $x$ & & 1 & \\
\hline Germany & $x$ & $x$ & $x$ & $x$ & $x$ & 1 & & \\
\hline Greece & $x$ & $x$ & & $x$ & & & 1 & \\
\hline Hungary & $x$ & $x$ & $x$ & $x$ & $x$ & & & 1 \\
\hline Ireland & $x$ & $x$ & $x$ & $x$ & & 1 & & \\
\hline Israel & $x$ & & & $x$ & $x$ & & 1 & \\
\hline Italy & $x$ & $x$ & & & & & 1 & \\
\hline Luxembourg & $x$ & $x$ & & & & & 1 & \\
\hline Netherlands & $x$ & $x$ & $x$ & $x$ & $x$ & 1 & & \\
\hline Norway & $x$ & $x$ & $x$ & $x$ & $x$ & 1 & & \\
\hline Poland & $x$ & $x$ & $x$ & $x$ & $x$ & & & 1 \\
\hline Portugal & $x$ & $x$ & $x$ & $x$ & $x$ & & 1 & \\
\hline \multicolumn{2}{|c|}{ Russian Federation } & & $x$ & $x$ & $x$ & & & 1 \\
\hline Slovakia & & $x$ & $x$ & $x$ & & & & 1 \\
\hline Slovenia & $x$ & $x$ & $x$ & $x$ & $x$ & & & 1 \\
\hline Spain & $x$ & $x$ & $x$ & $x$ & $x$ & & 1 & \\
\hline Sweden & $x$ & $x$ & $x$ & $x$ & $x$ & 1 & & \\
\hline Switzerland & $x$ & $x$ & $x$ & $x$ & $x$ & 1 & & \\
\hline Turkey & & $x$ & & $x$ & & & & \\
\hline Ukraine & & $x$ & $x$ & $x$ & & & & 1 \\
\hline United Kingdom & $x$ & $x$ & $x$ & $x$ & $x$ & 1 & & \\
\hline
\end{tabular}

Note: Edition 1.0 of ESS round 5 is used. 
Table A3. Countries of Ancestry on the Mother's Side and Summary Statistics.

\begin{tabular}{|c|c|c|c|c|c|c|c|c|}
\hline $\begin{array}{l}\text { Country } \\
\text { Code }\end{array}$ & $\begin{array}{l}\text { Trust, mother's } \\
\text { country of birth }\end{array}$ & $\begin{array}{l}\text { Count of 2nd } \\
\text { generation } \\
\text { immigrants }\end{array}$ & $\begin{array}{c}\text { Country } \\
\text { Code }\end{array}$ & $\begin{array}{l}\text { Trust, mother's } \\
\text { country of birth }\end{array}$ & $\begin{array}{c}\text { Count of } 2 \text { nd } \\
\text { generation } \\
\text { immigrants }\end{array}$ & $\begin{array}{c}\text { Country } \\
\text { Code }\end{array}$ & $\begin{array}{l}\text { Trust, mother's } \\
\text { country of birth }\end{array}$ & $\begin{array}{l}\text { Count of } 2 \text { nd } \\
\text { generation } \\
\text { immigrants }\end{array}$ \\
\hline$A D$ & 0.207 & 1 & $\mathrm{FI}$ & 0.565 & 204 & $M X$ & 0.241 & 3 \\
\hline$A L$ & 0.256 & 9 & FR & 0.219 & 251 & MY & 0.088 & 7 \\
\hline AM & 0.247 & 10 & GB & 0.359 & 158 & NG & 0.219 & 9 \\
\hline$A R$ & 0.196 & 25 & GE & 0.185 & 29 & $\mathrm{NL}$ & 0.506 & 104 \\
\hline AT & 0.327 & 179 & $\mathrm{GH}$ & 0.085 & 7 & NO & 0.664 & 66 \\
\hline $\mathrm{AU}$ & 0.446 & 11 & GR & 0.237 & 75 & $\mathrm{NZ}$ & 0.500 & 4 \\
\hline$A Z$ & 0.205 & 17 & GT & 0.157 & 1 & $\mathrm{PE}$ & 0.075 & 5 \\
\hline BA & 0.219 & 67 & $\mathrm{HK}$ & 0.411 & 6 & $\mathrm{PH}$ & 0.071 & 17 \\
\hline$B D$ & 0.222 & 7 & $H R$ & 0.229 & 97 & PK & 0.274 & 54 \\
\hline $\mathrm{BE}$ & 0.313 & 79 & $\mathrm{HU}$ & 0.269 & 145 & $P L$ & 0.233 & 437 \\
\hline$B G$ & 0.270 & 52 & ID & 0.456 & 82 & PR & 0.124 & 1 \\
\hline BR & 0.064 & 35 & IE & 0.415 & 113 & PT & 0.174 & 121 \\
\hline BY & 0.286 & 121 & IL & 0.235 & 2 & RO & 0.168 & 192 \\
\hline$C A$ & 0.445 & 24 & IN & 0.346 & 86 & $\mathrm{RU}$ & 0.276 & 1039 \\
\hline $\mathrm{CH}$ & 0.438 & 32 & $1 \mathrm{Q}$ & 0.440 & 147 & SE & 0.635 & 63 \\
\hline $\mathrm{CL}$ & 0.203 & 14 & IR & 0.336 & 70 & SG & 0.147 & 2 \\
\hline $\mathrm{CN}$ & 0.542 & 12 & IS & 0.413 & 8 & SI & 0.182 & 7 \\
\hline $\mathrm{CO}$ & 0.120 & 4 & IT & 0.317 & 472 & SK & 0.213 & 180 \\
\hline CS & 0.276 & 47 & JO & 0.295 & 4 & $\mathrm{TH}$ & 0.415 & 10 \\
\hline CSS & 0.153 & 1 & $J P$ & 0.416 & 5 & TR & 0.113 & 376 \\
\hline $\mathrm{CY}$ & 0.128 & 11 & KG & 0.167 & 5 & TW & 0.296 & 1 \\
\hline$C Z$ & 0.267 & 160 & $\mathrm{KR}$ & 0.317 & 2 & TZ & 0.081 & 2 \\
\hline $\mathrm{DE}$ & 0.341 & 666 & LT & 0.262 & 34 & UA & 0.295 & 255 \\
\hline DK & 0.588 & 51 & LU & 0.248 & 14 & UG & 0.078 & 1 \\
\hline DO & 0.264 & 2 & LV & 0.206 & 31 & US & 0.411 & 137 \\
\hline $\mathrm{DZ}$ & 0.112 & 115 & MA & 0.194 & 365 & UY & 0.248 & 8 \\
\hline $\mathrm{EE}$ & 0.242 & 17 & MD & 0.182 & 19 & VE & 0.148 & 5 \\
\hline EG & 0.280 & 56 & MK & 0.111 & 28 & VN & 0.478 & 13 \\
\hline ES & 0.328 & 142 & $\mathrm{ML}$ & 0.175 & 3 & ZA & 0.198 & 10 \\
\hline ET & 0.244 & 18 & MT & 0.188 & 4 & ZW & 0.112 & 2 \\
\hline
\end{tabular}

Note: Country codes following ISO-3166. Trust is measured between 0 and 1, where 1 corresponds to 'most people can be trusted.'

The average across countries is 0.27 , and the standard deviation is 0.135 (both unweighted). 
Table A4. Demographic Estimates in the Full and Immigrant Samples.

\begin{tabular}{|c|c|c|c|}
\hline Dependent variable: Trust & $\begin{array}{l}\text { Full sample } \\
\text { (1) }\end{array}$ & $\begin{array}{l}\text { Immigrant } \\
\text { mother } \\
(2)\end{array}$ & $\begin{array}{l}\text { Immigrant } \\
\text { father } \\
\text { (3) }\end{array}$ \\
\hline \multirow[t]{2}{*}{ Age } & -0.015 & -0.019 & -0.023 \\
\hline & $(0.001)^{* * *}$ & $(0.012)$ & $(0.012)^{*}$ \\
\hline \multirow[t]{2}{*}{ Age squared/100 } & 0.016 & 0.024 & 0.025 \\
\hline & $(0.001)^{* * *}$ & $(0.011)^{* *}$ & $(0.012)^{* *}$ \\
\hline \multirow[t]{2}{*}{ Female } & -0.028 & -0.012 & -0.025 \\
\hline & $(0.004)^{* * *}$ & $(0.051)$ & $(0.052)$ \\
\hline \multirow[t]{2}{*}{ Married } & 0.128 & 0.182 & 0.035 \\
\hline & $(0.007)^{* * *}$ & $(0.074)^{* *}$ & $(0.072)$ \\
\hline \multirow[t]{2}{*}{ Never married } & 0.231 & 0.231 & 0.029 \\
\hline & $(0.011)^{* * *}$ & $(0.126)^{*}$ & $(0.120)$ \\
\hline \multirow[t]{2}{*}{ Upper secondary } & 0.205 & 0.359 & 0.247 \\
\hline & $(0.009)^{* * *}$ & $(0.087)^{* * *}$ & $(0.093)^{* * *}$ \\
\hline \multirow[t]{2}{*}{ College or university } & 0.710 & 0.902 & 0.958 \\
\hline & $(0.009)^{* * *}$ & $(0.091)^{* * *}$ & $(0.100)^{* * *}$ \\
\hline \multirow[t]{2}{*}{ Out of the labor force } & -0.079 & -0.162 & -0.055 \\
\hline & $(0.014)^{* * *}$ & $(0.078)^{* *}$ & $(0.061)$ \\
\hline \multirow[t]{2}{*}{ Unemployed } & -0.368 & -0.440 & -0.356 \\
\hline & $(0.014)^{* * *}$ & $(0.147)^{* * *}$ & $(0.186)^{*}$ \\
\hline \multirow[t]{2}{*}{ Low income } & -0.269 & -0.201 & -0.148 \\
\hline & $(0.006)^{* * *}$ & $(0.077)^{* *}$ & $(0.081)^{*}$ \\
\hline \multirow[t]{2}{*}{ Middle income } & 0.006 & 0.008 & -0.007 \\
\hline & $(0.005)$ & $(0.048)$ & $(0.056)$ \\
\hline \multirow[t]{2}{*}{ Catholic } & 0.037 & -0.065 & -0.034 \\
\hline & $(0.011)^{* * *}$ & $(0.080)$ & $(0.100)$ \\
\hline \multirow[t]{2}{*}{ Protestant } & 0.228 & 0.289 & 0.148 \\
\hline & $(0.019)^{* * *}$ & $(0.088)^{* * *}$ & $(0.103)$ \\
\hline \multirow[t]{2}{*}{ Orthodox } & 0.097 & 0.115 & 0.127 \\
\hline & $(0.031)^{* * *}$ & $(0.168)$ & (0.107) \\
\hline \multirow[t]{2}{*}{ Constant } & 4.918 & 4.888 & 5.108 \\
\hline & $(0.046)^{* * *}$ & $(0.339)^{* * *}$ & $(0.328)^{* * *}$ \\
\hline Country-by-year fixed effects & Yes & Yes & Yes \\
\hline R-squared & 0.172 & 0.126 & 0.117 \\
\hline Observations & 174857 & 7235 & 7535 \\
\hline
\end{tabular}

Notes: The dependent variable Trust is coded from 0 , 'can't be too careful,' to 10 , 'most people can be trusted.' Column (1) includes all observations. Columns (2) and (3) includes only second generation immigrants; column (2) study those with an immigrant mother and column (3) those with an immigrant father. All regressions include a full set of country of residence-by-year fixed effects. Data is from the second to fifth waves of the European Social Survey. Standard errors in paranthesis, which allow for clustering on the parent's birth country.

Significance stars, ${ }^{*} p<0.1,{ }^{* *} p<0.05,{ }^{* * *} p<0.01$. 